\title{
Association between transfusion of whole blood and recurrence of cancer
}

\author{
NEIL BLUMBERG, JOANNA M HEAL, PAUL MURPHY, MUKESH M AGARWAL, \\ CHRISTY CHUANG
}

\begin{abstract}
Transfusion affects the immune response to renal transplantation and may be associated with recurrence of various human neoplasms. Data from patients with colonic, rectal, cervical, and prostate tumours showed an association between transfusion of any amount of whole blood or larger amounts of red blood cells at the time of surgery and later recurrence of cancer. Recipients of one unit of whole blood had a significantly higher incidence of recurrence $(45 \%)$ than recipients of a single unit of red cells $(12 \%)$ $(p=0.03)$. Recipients of two units of whole blood also had a higher rate of recurrence $(52 \%)$ than those receiving two units of red cells $(23 \%)(p=0.03)$. Recipients of any amount of whole blood had similar recurrence rates $(38-52 \%)$. Recipients of four or more units of red blood cells had a higher rate of recurrence $(55 \%)$ than those receiving three or fewer units of red blood cells $(20 \%)(p=0.005)$. Mortality due to cancer in patients receiving three or fewer units of red blood cells $(2 \%)$ was similar to that in patients who did not have transfusions $(7 \%)$ and significantly lower than that observed in patients receiving three or fewer units of whole blood $(20 \%)(p=0.003)$. A proportional hazards risk analysis showed that transfusion of any whole blood or more than three units of red blood cells was significantly associated with earlier recurrence and death due to cancer.

These data support an association between transfusion and recurrence of cancer. They also suggest that some factor present in greater amounts in whole blood, such as plasma, may contribute to the increased risk of recurrence in patients who have undergone transfusion. Until the questions raised by retrospective studies of cancer recurrence and transfusion can be answered by prospective interventional trials with washed red blood cells, red blood cells should be transfused to patients with cancer in preference to whole blood when clinically feasible.
\end{abstract}

\section{Introduction}

A growing body of data shows that blood transfusions have immunological effects on patients and experimental animals beyond those of alloimmunisation to blood cell antigens. ${ }^{1-3}$ The best characterised clinical consequence is that of improved renal allograft survival in transfused patients compared with that in those not receiving homologous blood. These findings have led to studies on whether transfusion at the time of cancer surgery might be associated with immunological modulation of the patient and

Blood Bank, Department of Pathology and Laboratory Medicine and Hematology Unit of the Department of Internal Medicine, University of Rochester Medical Center, and American Red Cross Blood Services, Rochester, New York, USA

NLIL BLUMBERG, MD, associate professor of pathology and laboratory medicine and director, blood bank

JOANNA M HEAL, MRCP, assistant professor of internal medicine

PAUL MURPHY, MD, resident

MUKESH M AGARWAL, MD, residen

CHRISTY CHUANG, PHD, biostatistician, Upjohn Co, Kalamazoo, MI

Correspondence and requests for reprints to: $\mathrm{Dr} N$ Blumberg, Box 608, University of Rochester Medical Center, Rochester, NY 14642 (USA) unfavourable rates of tumour recurrence. The first study showing such an adverse relation was that of Burrows and Tartter on patients with colonic cancer ${ }^{4}$ which has been followed by numerous studies documenting associations between perioperative transfusion and poorer outcome in patients with cancers of the colon and rectum, ${ }^{56}$ lung,${ }^{78}$ breast, ${ }^{9}$ and cervix,${ }^{10}$ as well as soft tissue sarcomas. ${ }^{11}$ Some studies have failed to find such associations or have found small differences that are not significant. ${ }^{12-18}$ Furthermore, almost all studies have been retrospective reviews of medical records, subject to many biases, raising the possibility that the reported associations are due to unfavourable prognostic factors that are in turn linked to the likelihood of transfusion. ${ }^{12}$

The failure of some studies to confirm an association between tumour recurrence and transfusion may be due to local factors of cancer biology ${ }^{19}$ or treatment strategies or to the absence of a causal relation. Because transfusion practices vary greatly between clinicians and hospitals we hypothesised that differences in the kind of blood components transfused might have some bearing on the findings in different studies. Our own study of recurring colorectal tumours found a dramatic association between tumour recurrence and transfusion. A dose-response relation between number of transfusions and tumour recurrence, however, could not be discerned. This was surprising if an immunological mechanism analogous to that seen in renal allograft survival exists. A doseresponse relation between the number of transfusions and renal allograft survival has been clearly shown. ${ }^{1}$ Thus we analysed our data on patients who had undergone transfusion who had cancer of the colon, ${ }^{5}$ rectum,${ }^{5}$ cervix,${ }^{10}$ and prostate to see if differences in the amount and kind of transfusions were associated with varying recurrence and death rates.

\section{Patients and methods}

The methods used to collect data on patients with cervical and prostate cancer were identical with those reported in our retrospective study of colonic and rectal tumours. ${ }^{5}$ In brief, the names and identifying numbers of hospital patients seen between 1970 and 1982 with these diagnoses were retrieved from a computerised database and the medical record reviewed, collecting a variety of demographic, clinical, and treatment data. Transfusion data were also confirmed from blood bank records. Patients were included in the study if they had undergone surgery at our institution, had a documented follow up of at least six months, had no evidence of metastatic disease at diagnosis, and had an unambiguous history of transfusion and diagnosis of cancer. We designated patients as being in the transfusion groups if the transfusions occurred within one month before or after surgery. Patients receiving transfusions at other times were not included in this analysis. A multivariate analysis, including proportional hazards risk model, has been published for data on colorectal cancer, ${ }^{5}$ described in abstract for data on cervical cancer, ${ }^{10}$ and is in preparation for data on prostate cancer. The results for colonic, rectal, and cervical cancer suggested that transfusion was significantly associated with recurrence of cancer or death due to the tumour, or both, even after adjustment for clinical stage, anaemia at diagnosis, duration of surgery, patient's age, and so on.

All patients who had undergone transfusions received either red blood cells or whole blood or some combination of these components. A few received fresh frozen plasma (13/216) or platelet concentrate transfusions $(1 / 216)$. As initial analysis of the data suggested that recurrence was associated with transfusion of whole blood we grouped the patients into those who had received only red cells and those who had received at least one unit of whole blood. Patients who received only red cells and fresh frozen plasma or platelets or both, but no whole blood, were grouped with the patients receiving whole blood.

A total of 216 patients who underwent transfusion were analysed, of whom 120 had colonic or rectal cancer, 62 cervical cancer, and 34 prostate 
cancer. The 257 patients who did not have transfusions comprised 68 with colorectal cancer, 61 with cervical cancer, and 128 with prostate cancer. The numbers of recurrences and deaths for the colorectal, cervical, and prostate groups were, respectively $(54,20),(16,8),(19,6)$ for the transfusion group and $(6,3),(18,5),(44,11)$ for the control group. The proportion of the transfusion group who had recurrences or died because of cancer was significantly higher than that of the control group, except those with cervical cancer. The trends for recurrence and death reported by kind and amount of blood transfused were similar for each tumour. A breakdown of the data by tumour is available from the authors.

\section{Results}

We initially thought that whole blood transfusions might be associated with a greater risk of recurrence and death due to cancer than red blood cell transfusions. Table I shows data for incidence of recurrence and mortality for all of the cancer patients who had had transfusions. The data are stratified according to whether whole blood or red blood cells were given and the number of transfusions received. Differences in incidence of recurrence and mortality due to cancer observed among patients receiving one or two units of whole blood and those receiving the corresponding number of red blood

TABLE I-Recurrence rates and mortality by kind and amount of blood components received $(n=216)$

\begin{tabular}{|c|c|c|c|c|c|c|}
\hline \multirow[b]{2}{*}{ Units } & \multicolumn{3}{|c|}{ Recurrence rates } & \multicolumn{3}{|c|}{ Mortality } \\
\hline & $\begin{array}{l}\text { Whole blood } \\
(\text { No }(\%))\end{array}$ & $\begin{array}{l}\text { Red blood } \\
(\text { No }(\%))\end{array}$ & Probability $^{\star}$ & $\begin{array}{l}\text { Whole blood } \\
(\text { No }(\%))\end{array}$ & $\begin{array}{l}\text { Red blood } \\
(\text { No }(\%))\end{array}$ & Probability ${ }^{\star}$ \\
\hline 1 & $10 / 22(45)$ & $2 / 17(12)$ & 0.03 & $4 / 22(18)$ & $0 / 17$ & 0.09 \\
\hline 2 & $15 / 29(52)$ & $6 / 26(23)$ & 0.03 & $7 / 29(24)$ & $1 / 26(4)$ & 0.03 \\
\hline 3 & $9 / 24(38)$ & $2 / 7(29)$ & 0.52 & $4 / 24(17)$ & $0 / 7$ & 0.34 \\
\hline$>3$ & $34 / 71(48)$ & $11 / 20(55)$ & 0.38 & $15 / 71(21)$ & $3 / 20(15)$ & 0.40 \\
\hline
\end{tabular}

${ }^{\star} \mathrm{p}$ Values are for comparisons of whole blood to red cells by Fisher's exact test ${ }^{20}$; results for $\chi^{2}$ were similar.

TABLE II-Recurrence and mortality by kind and amount of blood components received

\begin{tabular}{lccccc}
\hline & $\begin{array}{c}\text { No of } \\
\text { patients }\end{array}$ & $\begin{array}{c}\text { Recurrences } \\
(\text { No }(\%))\end{array}$ & Probability* & $\begin{array}{c}\text { Deaths } \\
(\text { No }(\%))\end{array}$ & Probability* $^{\star}$ \\
\hline No transfusions & 257 & $68(26)$ & & $19(7)$ & \\
$\leqslant 3$ units of red cells & 50 & $10(20)$ & $0 \cdot 22$ & $1(2)$ & $0 \cdot 13$ \\
$\leqslant 3$ units of whole blood & 75 & $34(45)$ & 0.002 & $15(20)$ & 0.003 \\
$\geqslant 4$ units of red cells & 20 & $11(55)$ & 0.009 & $3(15)$ & $0 \cdot 20$ \\
$\geqslant 4$ units of whole blood & 71 & $34(48)$ & 0.0006 & $15(21)$ & 0.002 \\
\hline
\end{tabular}

* $p$ Values are for comparisons against the control group. Both $\chi^{2}$ and Fisher's exact test were employed giving identical results. ${ }^{20}$ The values for Fisher's exact test are shown.

\section{STATISTICAL ANALYSIS}

The methods detailed in our previous paper on colonic and rectal cancer were used. ${ }^{5}$ We used $\chi^{2}$ statistics to compare the transfusion and control groups with respect to the various prognostic factors. ${ }^{20}$ We also used such statistics to compare the incidence of recurrence or death in the various groups defined by the variables under study. These latter analyses were followed by statistical techniques that allow adjustment for differences in prognostic factors. The prognostic factors studied included age, date of surgery, duration of surgery, packed cell volume on admission, kind and amount of blood components received, type of cancer, and stage of cancer. To analyse this last factor for patients with different types of cancer we devised an improvised classification for statistical analysis. "Early stage" included patients with cervical cancers of stages $O$ and IA, colorectal cancers of stage $A$, and prostate cancers of stages $A_{1}$ and $A_{2}$. "Intermediate stage" included patients with cervical cancer stages of IB, IIA, and IIB, colorectal and prostate cancer stages $B_{1}$ and $B_{2}$. "Advanced stage" included patients with cervical cancer stages IIIA and IIIB, colorectal cancer stages $C_{1}$ and $C_{2}$, and prostate cancer stage $C$. We appreciated that this process could not yield precise data on the effect of stage on recurrence of cancer but wished to incorporate broadly representative information on stage in our study of prognostic factors that might be associated with transfusion and cancer recurrence. A multivariate stepwise logistic regression analysis was performed to determine which of the above prognostic factors were associated with whole blood transfusion. ${ }^{21}$

When fitting proportional hazards models to time to recurrence and survival time we first included as predictors all the previously prognostic factors but not the kind and amount of blood components transfused. ${ }^{22}$ The non-significant factors were excluded, and kind and amount of blood components were then added to the proportional hazards model to see if the change in the log likelihood after adding data on transfusion was significant. By entering information on transfusion last we could measure the impact of kind and amount of blood components transfused on time to recurrence and survival time after adjustment for other factors. We thus obtained an estimate of the effect on recurrence and death attributable to the type and amount of blood transfused. Kaplan-Meier's product limit method was used to estimate the unadjusted distributions of time to recurrence and survival times. ${ }^{23}$ cell units were significant. For those patients receiving three or more units of red cells the incidence of recurrence was not significantly different from that seen in any of the whole blood groups, regardless of number of whole blood units transfused.

Because of the observed trend toward a progressively lower incidence of recurrence and death among patients receiving three or fewer units of red cells, the data were further grouped into those receiving three or fewer units of red cells or whole blood and those receiving more than three. These data are shown in table II, along with the data on the control group. The recurrence and mortality of the control group and those receiving three or fewer units of red cells were not significantly different. These rates, however, were significantly lower than the recurrence and mortality in the patients receiving any amount of whole blood and those receiving more than three units of red cells. As the groupings of patients in this table are based on an initial analysis of variations in the data the $p$ values given may exaggerate the significance of the results. They are given only as rough indicators of the magnitude of differences in the incidence of events in the groups.

A multivariate stepwise logistic regression analysis showed that three prognostic factors were significantly associated with transfusion of any amount of whole blood or more than three units of red blood cells: surgery before 1975 (regression coefficient 1.0209), packed cell volume on admission of 41 or more $(0.6117)$ or less than $38(0.0048)$, and both early $(0.2060)$ and advanced $(0.3377)$ clinical stages of disease. Thus prognostic categories that might be expected to be related to time to recurrence and survival time were associated in a variable manner with transfusion of whole blood or more than three units of red blood cells. Such transfusions were significantly associated with both clinically favourable (packed cell volume 41 or more, early clinical stage) and unfavourable (packed cell volume less than 38 , advanced clinical stage) prognostic factors.

Proportional hazards models were constructed for time to recurrence and survival time, initially omitting the variables of kind and amount of blood components transfused. Age was positively associated with earlier recurrence (regression coefficient 0.013 ) but not with decreased survival time. Early clinical stage and packed cell volume of 38-40 were negatively associated with earlier recurrence (regression coefficients of -0.5954 and -0.7635 respectively) but not significantly associated with shortened survival time. Packed cell volume of less than 38 and duration of surgery of one hour or less and two to three hours were significantly associated with 


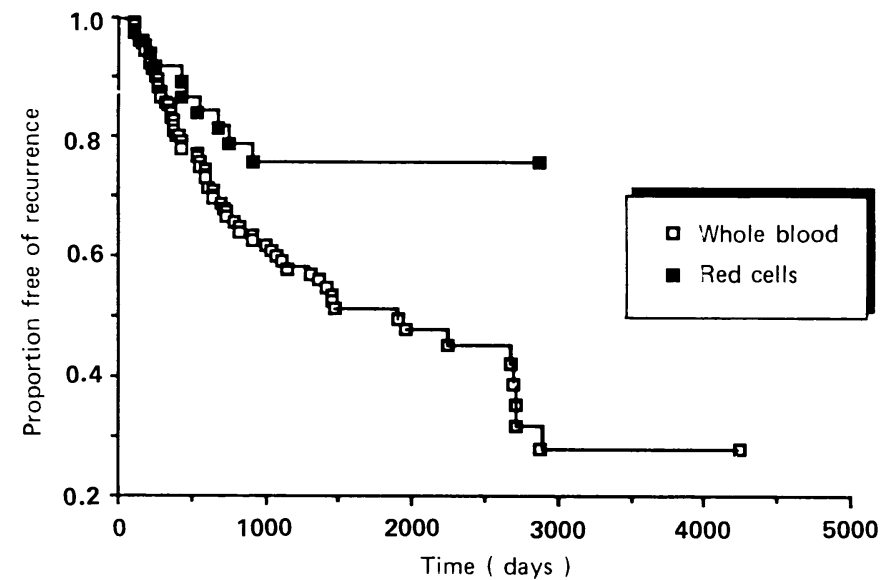

Curves of interval to recurrence in patients receiving transfusion with any amount of whole blood or $\geqslant 4$ units of red blood cells, and in patients receiving $\leqslant 3$ red blood cell transfusions. The terminal horizontal segments represent time from last observed recurrence to time of last censored observation. This includes 26 of the 50 patients receiving $\leqslant 3$ units of red blood cells and six of the 166 patients receiving any whole blood or $\geqslant 4$ units of red blood cells, all of whom were followed with no further recurrences. These curves are significantly different $(p=0.058$ by Breslow; $p=0.026$ by Mantel-Cox); curves for survival time also show longer survival for those receiving $\leqslant 3$ red blood cell transfusions (data not shown; $\mathrm{p}=0.02, \mathrm{p}=0.04$ ).

shorter survival times. Thus only one category significantly associated with transfusion of whole blood or more than three units of red blood cells (packed cell volume less than 38 ) was significantly associated with shortened survival in the proportional hazards model. It was not significantly associated with earlier recurrence. Conversely, a category significantly associated with transfusion of whole blood or more than three units of red blood cells (early clinical stage) was negatively associated with earlier recurrence.

Adding to the proportional hazards models the binary variable of any amount of whole blood transfusion (including those receiving more than three units of red cells) versus three or fewer units of red blood cell transfusions increased the log likelihood of both earlier recurrence $(p=0.047)$ and shortened survival $(p=0.029)$. The relative risk of earlier recurrence for those receiving any whole blood or more than three units of red blood cells was $2 \cdot 041(95 \%$ confidence interval $=1 \cdot 012,4 \cdot 115)$ and the relative risk of shortened survival was $9 \cdot 324(95 \%$ confidence interval $=$ $1 \cdot 260,68 \cdot 990)$

Kaplan-Meier's product limit estimates for unadjusted time to recurrence and survival time were calculated for patients who received transfusions of any whole blood or more than three units of red blood cells and for those who received three or fewer units of red cells. These estimates were also calculated for those receiving any whole blood versus those receiving any red blood cells, those receiving three or fewer units of whole blood versus those receiving three or fewer units of red blood cells, and those receiving more than three units of whole blood versus those receiving more than three units of red blood cells.

Data on patients without recurrence or who did not die of cancer were treated as censored. As expected, the most striking difference in estimates of the unadjusted time to recurrence or death was seen when patients receiving any whole blood or more than three units of red blood cells were compared with those receiving three or fewer units of red blood cells. The figure shows these curves for time to recurrence. Virtually identical curves were calculated when the data were analysed by clinical stage, but the results were not significant. The only other comparison that achieved significance at the $p=0.05$ level was that of survival time for patients receiving three or fewer units of whole blood versus those receiving three or fewer units of red blood cells. The patients receiving three or fewer transfusions of red blood cells survived for longer periods than those receiving three or fewer transfusions of whole blood ( $p=0.047$ by Mantel-Cox). The comparison of these two transfusion groups for time to recurrence showed the same trend but did not achieve significance (Breslow $\mathrm{p}=0 \cdot 15$; Mantel-Cox $\mathrm{p}=0.081$ ).

\section{Discussion}

Our data indicate that the association between transfusion and recurrence of cancer in some patients may be causal. There appears to be a distinct relation between the kind and amount of blood component transfused and the subsequent incidence of recurrence and death. Owing to the need to divide our data into discrete categories, the numbers of patients analysed is small and required pooling of data from three separate retrospective studies of transfusion and cancer recurrence. Although the biology and causes of tumour recurrence for these diseases are no doubt variable and multifactorial, the trends for recurrence and death associated with blood transfusions were virtually identical for each type of tumour. Furthermore, multivariate analysis suggested that the transfusion of any amount of whole blood or larger numbers of red blood cell concentrates is independently associated with earlier recurrence and death due to cancer. The data do not support the assertion that this relation is entirely due to whole blood transfusions being associated with other prognostic factors such as advanced clinical stage, advanced age, longer duration of surgery, or anaemia at the time of diagnosis. Although transfusions of any amount of whole blood or more than three units of red blood cells were more likely in patients treated before 1975, those with early and advanced clinical stages, and those with a packed cell volume of less than 38 and 41 or more, none of these latter individual categories were significant predictors of both time to recurrence and survival time when entered into proportional hazards models. In contrast, transfusion of any whole blood or more than three units of red blood cells was significantly associated with both earlier recurrence and death owing to cancer in the proportional hazards risk analysis.

In our clinical experience the decision to use whole blood rather than red cells is largely a matter of habit or conviction on the part of the surgeon or anaesthetist or availability from the blood bank. We know of no evidence to suggest that choice of blood component might be related to surgical skill, clinical stage, etc. This would be especially true, we believe, for transfusions of one or two units of blood. Our data suggest that previous studies might usefully be reexamined to see what kinds of blood components were given as well as the amount transfused. ${ }^{+6.911-18}$ Variations in blood component therapy practice may in part account for the different conclusions drawn in previous studies of transfusion and cancer recurrence.

If, in certain patients, the relation between transfusion and cancer recurrence is causal, the mechanisms implicated are obscure. Red blood cells and whole blood differ primarily in the amount of plasma transfused. Red blood cells contain perhaps $50-60 \mathrm{ml}$ of plasma and anticoagulant preservative solution, whole blood contains $250-300 \mathrm{ml}$, or five to six times as much. When platelet rich plasma is made before preparing red blood cells the red blood cells may be partially depleted of lymphocytes (perhaps by $40 \%$ in our laboratories). Most of the red blood cells transfused to the patients in our study were not depleted in lymphocytes (less than $20 \%$ of those who received transfusions we would estimate).

We think it likely that some substances in homologous plasma cause reduced immune function in patients with cancer given any whole blood or larger numbers of red blood cells (that is, more than three units). Suggestions that human plasma contains substances capable of causing immunosuppression in susceptible recipients have been made by others, ${ }^{24-27}$ and we believe our data support this hypothesis. Similarly, in an animal model of blood transfusion and tumour recurrence plasma transfusion was the blood component associated with the highest incidence of tumour growth. ${ }^{28}$ It is, however, also possible that recipients of plasma receive larger doses of known or unknown viral agents that are capable of modulating patient immune response and altering the ultimate outcome of the interaction between residual cancer and host defences. We think this less likely, but evidence of induction of immunological changes by even inactivated viruses has been reported in patients with cancer. $^{29}$

Controlled interventional trials of washed red blood cells depleted in plasma will be required to answer the questions raised by retrospective studies of cancer recurrence and blood transfusion. The practical implications of our data are that transfusions to patients with cancer should be performed only when clinically essential and that red blood cells should be used in preference to whole blood.

We thank Carol Cole for clerical and secretarial help throughout our investigations and the technical staff of the Blood Bank at Strong Memorial

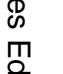 .

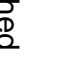

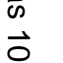 , .

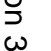

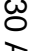

\section{.} . 
Hospital of the University of Rochester for helping to verify transfusion data. We thank Drs Dean Arvan, Jackson Beecham, and John Bennett for helpful discussions.

\section{References}

1 Opelz G, Terasaki PI. Improvement of kidnev-graft survival with increased numbers of blood transfusions. N Engl f.Med 1978:299:799-803.

2 Woodruff MFA, van Rood JJ. Possible implications of the effect of blood transfusion on allograft survival. Lancet 1983;1:1201-2.

Anonymous. Blood transfusion and allograft survival. Lancet 1984;i:830-1.

4 Burrows L, Tartter P. Effect of blood transfusions on colonic malignancy recurrence rate Lance $1982 ;$ ii: 662 .

5 Blumberg N, Agarwal MM, Chuang C. Relation between recurrence of cancer of the colon and blood transfusion. BrMed f 1985;290:1037-9.

6 Foster RS Jr, Costanza MC, Foster JC, Wanner MC, Foster CB. Adverse relationship between blood transfusions and survival after colectomy for colon cancer. Cancer 1985;55:1195-201.

7 Tartter PI, Burrows L, Kirshner P. Perioperative blood transfusion adversely affects prognosis after resection of stage I subset NO) non-oat cell lung cancer. $\mathcal{I}$ Thorac Cardiovasc Sur 1984;88:659-62.

8 Hyman NH, Foster RS Jr, DeMeules JE, Costanza MC. Blood transfusions and survival after lung cancer resection. Am f Surg 1985; 149:502-7.

9 Tartter PI, Burrows L, Papatestas AE, Lesnick G, Aufses AH Jr. Perioperative blood transfusion has prognostic significance for breast cancer. Surgery 1985;97:225-30.

10 Blumberg N, Agarwal $M$, Chuang $C$. A possible association between survival time and transfusion

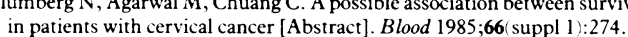

11 Rosenberg SA, Seipp CA, White DE, Wesley R. Perioperative blood transfusions are associated with increased rates of recurrence and decreased survival in patients with high-grade soft-tissue sarcomas of the extremities. Fournal of Clinical Oncology 1985;3:698-709.

12 Nathanson SD, Tilley BC, Schultz L, Smith RF. Perioperative allogeneic blood transfusionssurvival in patients with resected carcinomas of the colon and rectum. Arch Surg 1985;120:
13 Ota D, Alvarez L, Lichtiger B, Giacco (j, Guince V. Perioperative blood transfusions in patients with colon carcinoma. Transfusion 1985;25:392-4.

14 Foster RS Jr, Foster JC, Costanza MC. Blood transfusions and survival after surgery for breast cancer. Arch Surg 1984;119:1138-40.

15 Francis D, Judson R. Relation between recurrence of cancer of the colon and blood transfusion. $B r$ Hed 7 1985:291:544.

16 Frankish PD, McNee RK, Alley PG, W'oodfield DG. Relation between cancer of the colon and blood transtusion. BrMed 7 1985:290:1827.

17 Weiden PL, Bean MA, Schultz P. Thompson D. Perioperative blood transfusion does not increase risk of colorectal cancer recurrence [Abstract]. Blood 1984;64 suppl 1):232

18 Blair SD, Janvrin SB. Relation between cancer of the colon and blood transfusion. Br. Med 7 $1985 ; 290: 1516-7$

19 Johnson J Jr, Carstens R. Ethnic differences in the anatomical distribution of large bowel cancer [Abstract]. Clinical Res 1985:33:453.

20 Snedecor GW, Cochran WG. Statistical methods. 7 th ed. Iowa, USA: Iowa State University Press, 1980:124-30.

21 Anderson S, Auquier A, Hauck WW, Oakes D, Vandaele W, Wiesberg HI. Statistical methods for comparative studies. New York: Wiley, 1980:161-77.

22 Cox DR. Regression models and life tables. Foumal of the Roval Statistics Society 1972;34: 187-220 Series B.

23 Dixon WJ, Brown MB, Engelman L, et al. BMIPP statistical software. Los Angeles: University of California Press, 1981

24 Shearer GM, Levy RB. Noninfectious cofactors in susceptibility to AIDS: possible contributions of semen, HLA alloantigens and lack of natural resistance. Ann NY Acad Sci 1984;437:49-57.

25 Hsia S, Shockley RK, Lutcher CLK, et al. Unregulated production of virus and or sperm specific anti-idiotypic antibodies as a cause of AIDS. Lancet 1985;i:1212-4.

26 Shankey TV, Eyster ME. The acquired immune deficiency syndrome in hemophiliacs: a hypothesis. AIDS Research 1983;1:83-90.

27 Ablin RJ. Transglutaminase: a co-factor in aetiology of AIDS? Lancet 1985;i:813-4

28 Horimi T, Kagawa S, Ninomiva M, et al. Possible induction by blood transfusion of immunological tolerance against growth of transplanted tumors in mice. Acta Med Okavama immunological toler

29 Margolese $\mathrm{RG}$, Wainberg MA. Diminished responsiveness of virus co-incubated lvmphocytes to T cell growth factor in breast cancer patients. In: Gilmore N, W'ainberg MA, eds. Viral mechanisms of immunosuppression. New York: A R Liss, 1985: 193-203.

Accepted 13 fuly 1986

\title{
Incidence of rhesus immunisation after genetic amniocentesis
}

\author{
ANN TABOR， DONALD JERNE，JOHANNES E BOCK
}

\begin{abstract}
Of $655 \mathrm{Rh}$ negative women without anti-D antibody in their serum at genetic amniocentesis, 361 delivered a $R h$ positive infant. Prophylactic treatment with anti-D immunoglobulin was not given at amniocentesis. The women were followed prospectively, being given a screening test for antibody after amniocentesis, at delivery, and six months later. Five of these 361 women yielded a positive test result due to anti-D antibody. The immunisation rate after genetic amniocentesis was no higher than the spontaneous immunisation rate during pregnancy. Four women who had two amniocenteses in the same pregnancy and 34 women who had amniocentesis in two consecutive pregnancies with $R h$ positive fetuses were not immunised. Among six women with anti-D antibody in their serum before amniocentesis the titre of antibody increased in three. Amniocentesis may have worsened the outcome of these pregnancies.

These results suggest that the risk of immunisation in $\mathbf{R h}$ negative women is small.
\end{abstract}

Section of Clinical Genetics, Department of Obstetrics and Gynecology Y and Department of Pediatrics G, Rigshospitalet, University of Copenhagen, Denmark

ANN TABOR, MD, senior registrar

Blood Bank, Clinical Immunological Department, Rigshospitalet, University of Copenhagen, Denmark

DONALD JERNE, MD, senior registrar

Department of Obstetrics and Gynecology Y, Rigshospitalet, University of Copenhagen, Denmark

JOHANNES E BOCK, MD, chief obstetrician

Correspondence to: Dr A Tabor, Department of Gynecology and Obstetrics, Gentofte Hospital, 2900 Hellerup, Denmark.

\section{Introduction}

Amniocentesis has been associated with an increased incidence of feto-maternal haemorrhage, ${ }^{\prime 2}$ and fetal erythrocytes possess immunogenic $\mathrm{D}$ antigens at this stage of pregnancy. ${ }^{3}$ It remains to be shown whether amniocentesis induces anti-D antibodies in unsensitised $\mathrm{Rh}$ negative women. To protect the woman against this risk the World Health Organisation has recommended that a small dose of anti-D IgG be given at amniocentesis. ${ }^{+}$Giving this immunoglobulin, which is capable of passing through the placenta of a pregnant woman, could be associated with fetal morbidity and certainly makes interpretation difficult for the serological laboratory.

We attempted to evaluate whether prophylactic anti-D immunoglobulin at amniocentesis should be introduced in east Denmark, where antenatal prophylaxis is not administered.

\section{Patients and methods}

From 1 January 1981 to 31 December 1982, 4127 pregnant women who were planning to give birth in east Denmark had genetic amniocentesis performed at Rigshospitalet in Copenhagen. The study included 692 women who on admission were reported to be Rh negative; their indications for amniocentesis were maternal age $(298$ women $(43 \%))$, participation in a randomised trial of genetic amniocentesis $(166(24 \%))$, Down's syndrome in the family $(104(15 \%))$, and other reasons $(124(18 \%))$. Of these 692 women, 246 delivered a Rh negative child and 85 women were excluded for other reasons (fig 1). We therefore studied 361 women who had a $\mathrm{Rh}$ positive child. Table I shows the pertinent clinical data on these women.

All women on whom genetic amniocentesis was performed were followed up with a questionnaire filled in by the hospital where delivery took place. Besides stating complications occurring during pregnancy and delivery and after birth the questionnaire gave the rhesus state of the mother and child and information on whether immunoprophylaxis had been administered to 